\title{
Ensino médico e legitimação: a presença da homeopatia na Faculdade de Medicina do Paraná nos anos 1910
}

\section{Medical education and legitimation: the presence of homeopathy in the Faculty of Medicine of Paraná in the 1910s}

\author{
Renata Palandri Sigolo ${ }^{1}$
}

\begin{abstract}
RESUMO
A memória construída a partir da fundação da Universidade do Paraná e de seu curso médico retrata um de seus idealizadores, Nilo Cairo, como um personagem com duas facetas distintas. Este texto procura analisar como esta memória fragmentada nos impede de entender a implantação da Faculdade de Medicina do Paraná como um projeto que se harmoniza com o debate da medicina homeopática do início do século XX, suas estratégias de legitimação e os anseios de Nilo Cairo como homeopata.
\end{abstract}

Palavras-chave: história da saúde; medicina homeopática; ensino médico; Faculdade de Medicina do Paraná; Nilo Cairo.

\begin{abstract}
The memory built from the foundation of the University of Paraná and its medical school portrays one of its creators, Nilo Cairo, as a character with two distinct facets. This text analyzes how this fragmented memory prevents us from understanding the deployment of the Faculty of Medicine of Paraná as a project that fits with the discussion about homeopathic medicine in the early twentieth century, its strategies of legitimation and Nilo Cairo's aspirations as an homeopath.
\end{abstract}

Keywords: history of health; homeopathic medicine; medical education; Faculty of Medicine of Paraná; Nilo Cairo.

DOI: $10.1590 / 0104-4060.37812$

1 Universidade Federal de Santa Catarina. Departamento de História. Florianópolis, Santa Catarina, Brasil. Campus Universitário - CFH, Bairro Trindade. CEP: 88040-970. 
Mesmo sendo atuante propagandista e praticante da medicina homeopática, Nilo Cairo tem sua memória construída principalmente em torno do processo de criação e efetivação da Universidade do Paraná. Quando é lembrado, frequentemente seu "passado homeopático" é citado como um detalhe de sua atividade médica ou como um fato à parte de sua participação na fundação da Faculdade de Medicina do Paraná.

Este texto pretende abordar a criação da Faculdade de modo a apresentá-la como um projeto não desvinculado das convicções de Nilo Cairo como médico homeopata. Para tanto, convido o leitor a refletir sobre sua memória construída, ao mesmo tempo em que analiso o contexto da criação desta instituição de ensino, alinhavando-a às tentativas de legitimação da medicina homeopática na década de 1910.

Para comemorar o centenário de seu nascimento em novembro de 1974, a Universidade Federal do Paraná lançou um livreto que reproduzia a palestra promovida pelo Centro Acadêmico Nilo Cairo, em 1930, em sessão presidida pelo Dr. Vitor Ferreira do Amaral (outro fundador da Faculdade de Medicina e da Universidade do Paraná). O palestrante era o Dr. Jurandyr Manfredini, "o melhor biógrafo de Nilo Cairo", segundo a publicação (UNIVERSIDADE FEDERAL DO PARANÁ, 1974, p. 4).

Manfredini constrói um Nilo Cairo fragmentado, composto de diferentes aspectos: o "homem-representativo", o "divinisador (sic) da força", a "intemperança do saber", o "professor", o "sarcasta", o "philosopho", o "medico", o "homem-oceano" e, por fim, o "milagre da intelligencia" (UNIVERSIDADE FEDERAL DO PARANÁ, 1974). O orador apresenta, como ápice destes vários personagens, aquele que deveria permanecer na memória de todos:

Quando ficasse esquecido de todo o pathologista, o medico, o professor, o engenheiro, o agricultor, o zootechnico, Nilo subsistiria no milagre desta imponente Universidade, sortilegio do idealismo e da energia em ultima potenciação, idealismo e energia que são a força que é o mais delirante prato para o fetichismo da historia (UNIVERSIDADE FEDERAL DO PARANÁ, 1974, p. 6).

O Nilo de Manfredini é descrito como alguém incansável, forte, eloquente, qualidades necessárias para o empreendimento de fundação de uma universidade, parecendo justificar o que o psiquiatra chamava de "sarcasmo soberano", para ele a base sustentadora de sua inteligência: "corrosivo e maligno quasi sempre, não seleccionava as victimas” (UNIVERSIDADE FEDERAL DO PARANÁ, 
1974, p. 8). Ao empreendedor, somava-se o filósofo e o médico. Ao filósofo, o orador não poupava críticas, questionando como um "homem-oceano" poderia ter abraçado a filosofia comtiana. Manfredini buscava justificar esta filiação "muito mais pela coincidencia da iniciação mathematica que por disposições reaes do espírito" (UNIVERSIDADE FEDERAL DO PARANÁ, 1974, p. 8). Ao criticar a adesão de Nilo Cairo ao Positivismo, o biógrafo de Nilo Cairo parece desconsiderar a influência da corrente de pensamento para a criação das universidades brasileiras.

Já em relação ao médico homeopata, o psiquiatra procurava esquivar-se do que parecia ser um julgamento de difícil construção:

E o clinico, em Nilo Cairo, prolongando o sabio, afervorou-se em culto da homeopathia, em cujos mirionimos de diluição acreditava residir a energia 'medicatrix' immaterialisada capaz de recompôr os deniveis do rythmo vital. Era, assim, uma linha recta de coherencia que se traçava o doutrinario, indo imperiosamente de Bordeu à Hahnemann, de Montpellier a Dresde, da biologia vitalista ao espiritualismo therapeutico... Forremo-nos de exame critico que, a esse respeito, possa submetter os theorismos de Nilo Cairo ao chamado de contas das evoluções da medicina (UNIVERSIDADE FEDERAL DO PARANÁ, 1974, p. 10).

Novamente, Manfredini não explora a relação determinante entre o Positivismo defendido por Nilo Cairo e a homeopatia do início do século XX. Igualmente, se recusa a entrar abertamente no debate que opunha homeopatia e deixa escapar certa ironia ao descrever como "culto" e "espiritualismo terapêutico" o sistema médico criado por Hahnemann.

A homenagem aos cem anos de nascimento de Nilo Cairo não foi apreciada por David Carneiro, historiador paranaense também adepto do Positivismo. Traçando nova biografia, Carneiro publica um pequeno livro, em 1984, também editado pela Universidade Federal do Paraná. Nele, procura reestabeler o Nilo Cairo positivista enquanto constrói, segundo sua percepção, a trajetória que o levou a fundar a Universidade do Paraná, até sua morte.

Em primeiro lugar, David Carneiro trata de esclarecer que a ideia inicial da criação de uma universidade na terra das araucárias teria chegado a Nilo Cairo através de seu cunhado, que havia lido sobre a lei de liberdade de ensino de Rivadávia Correa. Cairo havia se entusiasmado pela possibilidade, uma vez que era, segundo Carneiro (1984, p. 6), 
[...] professor nato, médico por acaso, para complementação de instrução que the parecia indispensável [...] era um professor que desejava jogar-se à educação por convicções positivas, da mesma forma como procurava complementar seus conhecimentos enciclopédicos pelas mesmas convicções.

O Nilo Cairo apresentado por David Carneiro era dotado de um "conhecimento enciclopédico" confirmado por suas diversas formações, motivadas pela compreensão positivista da necessidade de acúmulo de conhecimento. Dentre estas, o papel de médico era secundário, suplantado pelo de educador, função exercida na instituição de ensino superior criada em 1912. Observa-se, igualmente, a dissociação do médico homeopata daquele que se tornou um dos fundadores da Universidade do Paraná.

Ao estabelecer as balizas com as quais interpreta a vida do médico paranaense, Carneiro (1984, p. 24) constrói o seguinte parâmetro: “[...] podemos dividir a vida de Nilo Cairo em duas fases: uma que vai até 1912, aos primeiros grandes esforços para que a Universidade do Paraná viesse a tornar-se realidade. A outra, de 1912 até seu desaparecimento em 1928". Este "antes e depois" da vida de Cairo aponta para a fundação da Universidade como divisor de águas, mas não estabelece um vínculo entre a atuação como homeopata e a criação da Faculdade de Medicina: apenas reforça o papel de Nilo Cairo como um dos "pais" da Universidade do Paraná.

Nas cartas de Nilo Cairo selecionadas por David Carneiro, temos um relato da fundação da Faculdade de Medicina:

[...] e desta vez fui eu só que ousou, porque não havia no começo, quem não deplorasse que o Nilo houvesse aberto o curso médico, ainda prematuro em Curitiba [...]. Folgo, pois, hoje, de lhe dar também os parabéns pela pertinácia com que v. Prosseguiu a sustentar minha ideia prematura... (CARNEIRO, 1984, p. 49).

Manfredini e Carneiro, apesar de terem formações intelectuais e interpretações completamente diferentes sobre Nilo Cairo, concordam em, ao menos, dois pontos: na ausência de vínculo entre a criação da Faculdade de Medicina do Paraná e a atuação de Cairo como médico homeopata e em suas fortes características psicológicas como essenciais para a fundação da Universidade do Paraná.

A personalidade exaltada de Nilo Cairo foi notada por outra descrição, tecida pelo médico homeopata José Emygdio Rodrigues Galhardo, por ocasião do $1 .^{\circ}$ Congresso Brasileiro de Homeopatia, em 1926. Galhardo não faz propria- 
mente uma biografia de Cairo, mas o descreve em diferentes trechos do livro do Congresso, em especial na nota de falecimento:

Extraordinario é o numero de obras que escreveu e publicou sobre pathologia, physiologia, therapeutica, materia medica, agricultura e veterinaria.

Varias são as polemicas em que se involveu (sic), defendendo a homeopathia onde fosse atacada e jamais houve quem lhe conquistasse a victoria. Sua these de doutoramento - Similia similibus curantur - é um dos maiores libellos contra a allopatia, formado de escriptos dos proprios allopathas.

Fundou e manteve por alguns anos a Revista Homoeopathica do Paraná, posteriormente Revista Homeopathica Brasileira, onde sua penna traçou variados e brilhantes estudos doutrinarios, criticos e scientificos.

Foi um dos principes fundadores da Universidade do Paraná, seu Estado natal, exercendo durante alguns annos o cargo de secretário, além de professor da respectiva Faculdade de Medicina (GALHARDO, 1928, p. 1012).

Era de se esperar que o discurso de Galhardo reconstruísse a trajetória de Nilo Cairo dando destaque às suas atividades como defensor da medicina de Hahnemann, mas não deixa de ser curioso o fato de não mencionar as cadeiras homeopáticas que o médico paranaense criou na Faculdade de Medicina do Paraná. É uma narrativa que contempla muito mais as atividades de Cairo como "defensor da homeopatia" do que como fundador da Universidade do Paraná, instituição que é o ponto de finalização da rota de Nilo Cairo e não seu início ou cume, como apontavam os dois biógrafos já citados.

O autor dos anais do Congresso retoma a atuação de Nilo Cairo no decorrer do livro, nas diferentes partes que compõem a História da Homeopatia no Brasil, tese apresentada por ele durante o evento e que representa a maior parte da obra. Sobre o período que antecede a criação da Universidade do Paraná, Galhardo (1928, p. 851) relata, na seção "Homeopathia no Paraná":

Dr. Nilo Cairo que em novembro de 1910 havia mudado sua residencia para a Capital Federal, regressou novamente à Curityba no inicio de março de 1911. A causa destas transferencias de residencias do D. Nilo Cairo será esclarecida em outro ponto desta Historia, quando me occupar da projectada Sociedade Homoeopathica Brasileira. 
Galhardo não retoma o fato e é preciso mergulhar em outras fontes para desvendar o que foi a Sociedade Homoeopathica Brasileira e qual foi sua possível ação em Nilo Cairo e na fundação da Faculdade de Medicina do Paraná. Ao separarem o "homeopata" do "fundador", os biógrafos aqui citados não se questionam da possibilidade da Universidade do Paraná e seu curso médico terem influências, mesmo que indiretas, da intensa batalha que homeopatia e alopatia travaram no início do século XX. Portanto, é necessário acompanhar o debate entre os homeopatas do período para ter um conhecimento mais amplo do contexto.

A introdução, no Brasil, de uma medicina de cunho vitalista como a homeopatia foi marcada pela contestação à "outra medicina", ou como denominavam os adeptos de Hahnemann, a alopatia. Esta rivalidade foi construída desde seu nascimento na Europa (GIORDAN; RAICHVARG, 2010) e esteve presente de forma muito evidente na construção de condições para seu estabelecimento e continuidade em território nacional. O desenvolvimento de seus paradigmas é marcado de rupturas e continuidades que devem ser consideradas no contexto da medicina europeia de fins do século XVIII: o estabelecimento de suas bases teóricas pelo médico alemão Samuel Hahnemann deve ser compreendido tendo como partida a reformulação dos conceitos próprios da medicina da época (PRIVEN, 2005).

Uma das formas de legitimação e propagação da homeopatia no Brasil, bem como da alopatia, foi a formação de cursos médicos acadêmicos. Desde a vinda do médico homeopata Benoît Mure em 1842, várias foram as tentativas de introduzir a homeopatia no meio acadêmico.

No início do século XX, o debate sobre a impotância do diploma médico para os homeopatas ocorre em um contexto diferente do momento de introdução da homeopatia no Brasil. O ano de 1912 foi bastante neste sentido. Neste ano, o Instituto Hahnemanniano do Brazil, principal associação homeopática brasileira da qual participava Nilo Cairo, promoveu uma reforma em seus estatutos.

A reforma proposta em 1912 redefiniu as formas de adesão ao Instituto Hahnemanniano, estabelecendo as categorias de sócio efetivo, correspondente, honorário e benemérito. A primeira e mais importante classe de sócios era assim descrita: "Art. 6. : Socios effectivos podem ser todos os que, residentes no Districto Federal, ou em um lugar proximo que lhes permitta comparecer às sessões, professarem a homoeopathia" (ACTA..., 1912a, p. 250). Apesar da aprovação da proposta, a discussão acerca das modificações no estatuto dos sócios estava apenas começando.

Dois médicos se manifestaram contrários às decisões sobre o estatuto: Nilo Cairo, já residente em Curitiba, e Alcides Nogueira. Para este último, as reformas alteravam a exigência de habilitação e preparo científico que os 
candidatos a sócio do Instituto Hahnemanniano deveriam ter (ACTA, 1912c, p. 284-286). Suas observações são levadas a reuniões posteriores onde, acrescidas das críticas de Nilo Cairo, são alvos de debate em várias sessões.

Enquanto isso, Nilo Cairo e seu colega homeopata, Dias da Cruz, se digladiavam nas páginas dos Annaes de Medicina Homoeopathica e da Revista Homoeopathica Brazileira. Em seus artigos, Nilo Cairo argumentava no sentido de demonstrar que, admitindo pessoas leigas, o Instituto retrocederia aos tempos dos primeiros sucessores de Mure, tempos do "charlatanismo homoeopathico", onde se "fabricavam curandeiros as toneladas" (CAIRO, 1912a, p. 25). Sua aversão pelo que julgava ser um retrocesso do Instituto Hahnemanniano era tamanha que chegava a convidar seus colegas homeopatas a se associarem às associações alopáticas, por considerar serem os únicos centros científicos médicos existentes no Brasil, naquele momento (CAIRO, 1912b, p. 40-42).

Dentre as reprimendas recebidas por Cairo por parte dos membros do Instituto Hahnemanniano, estava a censura de Saturnino Cardoso que se mostrava espantado diante da posição do colega:

Diz que se admira profundamente de que um homem do valor intellectual do Sr. Dr. Nilo Cairo e filiado, como publicamente o tem demonstrado, a uma doutrina philosophica que condemna todos os monopolios e privilegios e principalmente os privilegios cientificos, julgando de nenhum valor os diplomas conferidos de taes privilegios para attestar o saber, venha com lamentavel contradicção ser entre nós o paladino, tornar-se o defensor imperterrito (sic) do privilegio do diploma (ACTA, 1912d, p. 308).

Era realmente estranho que Cairo, adepto da filosofia de Comte e da liberdade profissional, adotasse uma postura tão rígida em relação à exigência de um aparato que legitimasse a prática da medicina homeopática. Porém, é preciso lembrar que, mesmo em suas defesas ao livre exercício da medicina, o homeopata paranaense deixava claro sua opinião sobre a necessidade de transitoriedade da liberdade profissional (CAIRO, 1906, p. 1-3).

Ao defender o pré-requisito de que os sócios efetivos fossem diplomados, o médico paranaense ressaltava que sua luta se justificava pela necessidade dos médicos homeopatas portarem um documento de habilitação profissional reconhecido oficialmente. Se referindo a si mesmo na terceira pessoa, ele sublinhava:

Não é que o Sr. Nilo Cairo, infiel à sua educação filosófica, fizesse questão do monopólio official do diploma. Não. [...] Se o Dr. Nilo Cairo queria 
apenas que todo o socio do Instituto fosse um profissional de medicina ou da pharmacia homoeopathicas, com diploma de uma escola official, ou de uma Faculdade Livre ou licença de uma Directoria Sanitaria, enfim, um documento publico de habilitação profissional. Era só (CAIRO, 1912d, p. 80).

Se a homeopatia queria ser a "medicina verdadeira", colocando-se no lugar conquistado pela alopatia, teria que adotar as mesmas estratégias de legitimação, sob pena de não ser levada a sério: criar espaços exclusivamente científicos, neste sentido, auxiliava o reconhecimento da medicina de Hahnemann, principalmente na comunidade médica.

O debate de 1912, que confrontou Nilo Cairo aos seus colegas do Instituto Hahnemanniano começara, na verdade, um ano antes. Este atrito explica, ao menos em parte, seu retorno ao Paraná. Em janeiro de 1911, Cairo publicou uma nota na revista em que era editor, com o objetivo de explicar a mudança de endereço da Revista Homoeopathica Brazileira. Inicialmente em Curitiba, desde 1906, o periódico é transferido ao Rio de Janeiro, em 1910, retornando à Capital do Paraná em 1911. Esta rápida estadia na capital federal é justificada por ele:

Mudando, em novembro ultimo, minha residencia para a capital da Republica, levou-me apenas um objectivo: de prévio acordo com alguns confrades daquella metropole, a fundação de uma associação leiga humanitária (a Sociedade Homeopathica Brazileira) destinada a manter uma Polyclinica Homeopathica para indigentes, um Hospital Homeopathico e uma pequena Escola de Medicina Homeopathica.

Esta associação deveria ser fundada à sombra do Instituto Hahnemanniano do Brazil, única associação scientifica de medicos homeopathas que então existia no Brazil e tinha sua séde no Rio, e cuja presidencia era occupada pelo Sr. Dr. JOAQUIM MURTINHO, com cujo prestigio social e político todos contávamos (CAIRO, 1911, p. 71).

Continuando seu relato, conta como preparou, cuidadosamente, todos os detalhes do empreendimento, desde o capital necessário para realizá-lo, até a elaboração dos seus estatutos, bem como a conquista do apoio de vários colegas, como Licinio Cardoso, Dias da Cruz e Theodoro Gomes. No entanto, seus planos redundam em fracasso, segundo ele, devido ao "egoísmo, o descaso e a indifferença pela causa da Homeopathia" (CAIRO, 1911, p. 74). 
Ao projetar a fundação da Sociedade Homeopathica Brazileira, filiada ao Instituto Hahnemanniano, Cairo pensava em estabelecer uma instituição que, num primeiro momento, apoiasse a criação de um hospital e uma escola homeopática. Porém, não recebe o apoio necessário de Joaquim Murtinho, médico que exercera cargos políticos e no qual os homeopatas da época depositavam suas esperanças (LUZ, 1996, p. 185-190).

Incansável crítico, Nilo Cairo escreve vários artigos censurando o Instituto e Joaquim Murtinho, presidente da instituição desde 1904 (GALHARDO, 1928, p. 796). Neste momento Murtinho falece e Cairo dedica a ele um número inteiro da Revista Homeopathica Brazileira. Apesar da homenagem, o médico paranaense não muda sua opinião sobre o antigo presidente do Instituto, insistindo na importância que teria seu projeto para o ensino da homeopatia no Brasil.

Porém, o fracasso de Nilo Cairo não significou a ausência de faculdades homeopáticas. Logo após a rejeição da proposta de organização da Sociedade Homeopathica Brazileira e aproveitando a liberdade de ensino proporcionada pela Lei Rivadávia, sancionada em abril de 1911, foi fundada, por adeptos da homeopatia não filiados ao Instituto Hahnemaniano, a Faculdade de Medicina Homeopathica do Brasil, gerando uma série de controvérsias no meio homeopático.

A recém-fundada Faculdade não mantinha vínculo com o Instituto Hahnemanniano e este e outros problemas foram levantados por membros do Instituto: a rapidez da criação, o programa do curso médico, além de cadeiras importantes terem sido entregues a alopatas (NOGUEIRA, 1912, p. 270-272). Apesar das censuras, dois grupos se posicionavam de maneira diferente em relação ao assunto: os que apoiavam a criação mesmo que apressada da faculdade e aqueles que preferiam ponderar melhor sobre as bases da fundação de uma instituição de ensino exclusivamente homeopática (CRUZ FILHO, 1912, p. 300). Nilo Cairo aproveitava o cenário de críticas para relançar sua ideia malograda de constituir a Sociedade Homeopathica Brazileira, censurando o Instituto por não ter tomado a iniciativa.

Diante do quadro de deficiências apresentadas, o Instituto Hahnemanniano estabeleceu como condições para seu apoio à já fundada Faculdade de Medicina Homeopathica que houvesse modificações em seu programa. São indicados membros do Instituto para fazer parte da Faculdade e promover a reforma de seus estatutos. Uma das modificações previa a substituição de um de seus fundadores, Antonio Guilherme Cordeiro, por Dias da Cruz Filho, o que provocou uma ação judiciária movida pelo primeiro. O impasse é resolvido com a criação de outra faculdade, a Faculdade Hahnemanniana, a partir da antiga Faculdade de Medicina Homeopathica, que foi extinta (LUZ, 1996, p. 201-202). 
As promessas de modificações na Faculdade entusiasmaram Nilo Cairo que felicita os colegas do Instituto, sem deixar de lhes dirigir um lembrete:

Resta agora fazermos um derradeiro apello: é que exijam de novo o attestado de habilitação, diploma ou licença para ser socio do Instituto Hahnemanniano do Brazil, conservando-lhe assim o seu caracter medico e scientifico, e fundem sem tardança a Sociedade Homeopathica Brazileira e o Dispensario Homeopathico, para coroamento da empreza, a que metteram hombros com tanto denodo. E o futuro da Homeopathia no Brazil estará garantido. Estamos publicando em nossas paginas todos os projectos que, em 1910, organisou o Sr. Dr. Nilo Cairo, na tentativa infructifera que fez naquelle anno e começo de 1911, para fundar essas instituições, que só agora, depois da morte do Sr. Dr. Joaquim Murtinho, conseguiram ser realizadas (CAIRO, 1912e, p. 58).

Apesar de apoiar a nova Faculdade, Cairo não desiste de criticar as posições do Instituto Hahnemanniano em relação a não exigência de diploma para sócios efetivos naquela entidade. Isto se radicaliza, uma vez que já existia uma Faculdade homeopática e, após muitas ofensas dirigidas ao Instituto (Nilo Cairo chegou a denominá-lo de Instituto de Miscellaneas Homeopathicas), e de não mais reconhecer a autoridade científica da instituição, o médico paranaense pede demissão pela segunda vez:

Curityba (Paraná), 21 de Julho de 1912.

Ilmo Sr. Presidente do Instituto Hahnemanniano do Brazil. - Tendo resolvido, por motivos particulares, que só a mim dizem respeito, deixar de fazer parte desse Instituto, renuncio, nesta data, depondo-o nas vossas mãos, o meu logar de socio correspondente, o que vos peço mandeis consignar em acta. Aproveito a opportunidade para apresentar-vos os protestos da minha elevada consideração e profundo respeito e pedir-vos transmitir aos demais membros do Instituto os meus agradecimentos e profunda gratidão pelo distincto apreço com que sempre fui tratado no seio da corporação. (o grypho é do auctor)

$\mathrm{Cr}^{\circ} \mathrm{e} \mathrm{am}^{\circ}$ mto. obr ${ }^{\circ}$

(Assignado) Dr. Nilo Cairo (ACTA, 1912c, p. 376-377).

O Instituto Hahnemanniano decide aceitar o pedido, registrando em ata um "voto de profunda magua" pela saída do médico paranaense que, no mesmo 
ano, juntamente com Victor Ferreira do Amaral, funda a Universidade do Paraná, favorecida pela Lei Orgânica de Ensino. A Lei Rivadávia também estimulou um front precioso para os discípulos de Hahnemann, ao facilitar a criação das faculdades homeopáticas anteriormente abordadas e que seriam centros de difusão do saber homeopático e de reconhecimento de seus locutores.

Gradativamente, a Faculdade Hahnemanniana buscava equiparar seu ensino ao das faculdades de medicina alopáticas, não dispensando as disciplinas regulares de um curso médico e nem o ensino da anatomia em cadáveres. Foi construído um discurso de igualdade entre a medicina alopática e a homeopática cujo ápice pode ser observado na inauguração do curso de propedêutica, em 1914, por Licínio Cardoso:

Não é propriamente uma propedeutica homeopathica o que ides aprender aqui. Não: a medicina é uma só, embora a variedade nos processos therapeuticos. O problema biologico cuja resolução compete ao homem é trabalhar pela reversão dos casos pathologicos ao dominio da biologia normal. Não ha duas biologias, nem duas pathologias (FACULDADE..., 1914, p. 493).

É nesse quadro de construção de uma aparente concórdia entre homeopatia e alopatia que é criado o curso médico da Universidade do Paraná. Depois da Lei Rivadávia, o debate sobre a presença da homeopatia no meio acadêmico tendia muito mais para a criação de faculdades exclusivamente homeopáticas do que para a inserção de cadeiras médicas nos cursos alopáticos. Sobre o tema, Nilo Cairo havia se declarado mais favorável à criação de faculdades exclusivas do que pela introdução de cadeiras homeopáticas (CAIRO, 1909, p. 149-150). Porém, na criação do curso médico em Curitiba, Nilo Cairo muda de ideia e de estratégia. A listagem de cadeiras e sua distribuição, no curso de Medicina, previam a existência das disciplinas de Homeopatia e Terapêutica Homeopática e Clinica Homeopática, a serem ministradas por Cairo no quinto ano de Medicina, que também era Secretário e professor nas cadeiras de Elementos de Fisiologia e Patologia Geral (disciplina não homeopática) e de Farmacologia Homeopática nos cursos de Odontologia e de Farmácia (cursos organizados com o de Medicina e Cirurgia na Faculdade) (UNIVERSIDADE DO PARANÁ, 1913, não paginado).

As disciplinas de homeopatia foram empossadas por Cairo em 1913, por designação do Conselho Superior da Universidade (UNIVERSIDADE DO PARANÁ, 1920, f. 5), que também o nomeou para as cadeiras das citadas 
disciplinas de Elementos de Fisiologia e Patologia Geral e de Farmacologia Homeopática, em janeiro de 1914. O Livro de Assentamentos dos Professores da Faculdade de Medicina registra, como início de funcionamento das disciplinas lecionadas nos cursos de Odontologia e Farmácia, a data de 17 de março de 1914; contudo, nada consta sobre as cadeiras de homeopatia ofertadas ao curso de Medicina e Cirurgia. No Relatório Geral da Universidade do Paraná de 1914, estas cadeiras não constam no quadro de distribuição das disciplinas do curso (1. ${ }^{\circ}$ ao $5 .^{\circ}$ ano), estando a cargo de Nilo Cairo apenas as cadeiras de Química Médica e Pathologia Geral, dando a ideia de que as disciplinas Homeopatia e Terapêutica Homeopática e Clinica Homeopática teriam sido criadas, mas não lecionadas. Algo semelhante, aparentemente, aconteceu com a disciplina Farmacologia Homeopática para o curso de Odontologia, pois mesmo constando do Livro de Assentamentos dos Professores da Faculdade de Medicina, não existe relatório da disciplina para Odontologia no final de 1914 (UNIVERSIDADE DO PARANÁ, 1914b, p. 6).

Já o curso de Farmácia apresentava, em seu programa do ano de 1914, a disciplina de Farmacologia Homeopática a cargo do Dr. Nilo Cairo (UNIVERSIDADE DO PARANÁ, 1914a, p. 7-8). O conteúdo do programa desta cadeira, a oitava do curso, era muito similar a outro elaborado pelo homeopata quando projetava a Escola Livre de Homeopatia, no Rio de Janeiro (CAIRO, 1912e, p. 59-61). Esta disciplina, porém, cessou de ser ofertada em 1915, não constando mais no Relatório Geral daquele ano (UNIVERSIDADE DO PARANÁ, 1915).

Apesar da breve vida das cadeiras homeopáticas na Universidade do Paraná, elas revelam a tentativa de Nilo Cairo em contribuir para a disseminação e legitimação da homeopatia no local onde tinha se estabelecido, naquele momento de sua vida. No caso das matérias homeopáticas do curso de Medicina e Cirurgia, elas se situavam exatamente no quinto ano do curso, momento em que, segundo Dias da Cruz Filho, Cairo havia afirmado ser perfeito para a introdução do aprendizado da homeopatia em uma escola médica alopática (ACTA, 1912b, p. 276).

Após seus planos de fundação da Sociedade Homeopathica Brasileira, Cairo defendeu a formação do médico homeopata única e exclusivamente em faculdades especificamente hahnemannianas. Apesar disso, não é de se espantar a tomada de posição do médico paranaense em introduzir cadeiras homeopáticas na Universidade do Paraná: vindo de uma experiência frustrada de criação de uma escola homeopática, possuindo todos os programas necessários para constituí-la, o homeopata abraça a ideia da Universidade no Paraná e, dentro dela, uma Faculdade de Medicina. Sendo intenso propagandista da medicina homeopática, é bem possível que tenha visto na instituição o local perfeito para a difusão de seus ideais. 
Independente de disciplinas, que existiram por pouco tempo ou, como no caso daquelas para o curso de Medicina e Cirurgia, não passaram de uma proposta. Nilo Cairo continuava a disseminar a medicina de Hahnemann, sempre tendo como pano de fundo a filosofia comtiana. Em suas aulas no curso de Odontologia, quando ensinava Fisiologia, o homeopata não deixava de pregar a importância de compreender as questões biológicas tendo como pano de fundo a filosofia positivista, nem de valorizar o estudo da medicina vitalista, defendendo a visão do ser humano como único (CAIRO, 1916).

O curso de Medicina e Cirurgia da Universidade do Paraná recebeu outras influências do médico homeopata, além de suas cátedras. Quando da formação do curso médico na academia paranaense, uma das críticas incidiu sobre a ausência de cadáveres em número suficiente para o estudo da Anatomia. É muito provável que o pequeno número de corpos para a dissecação ocorresse mais por opção do que carência: desde sua tese Similia Similibus Curantur, Nilo Cairo defendia o uso de desenhos e manequins para este estudo, posição que viria a ratificar em suas observações sobre o estudo anatômico, na Faculdade de Medicina Homeopathica criada no Rio de Janeiro (CAIRO, 1912c, p. 70-72). Comentando com Romário Martins, quando este visitava a Universidade, sobre o ensino de anatomia nesta, Cairo afirmara:

Até hoje, desde os meus tempos de estudante de anatomia, nunca pude compreender as vantagens de se retalhar cadaveres em busca de órgãos já conhecidos e cujas relações a dissecção, por sua própria natureza, destrói. Faço, pois, votos para que o meu ilustre colga que proficientemente leciona esta materia na nossa Universidade, rompa decisivamente com a rotina do defunto, adotando em sua cadeira o belo e humano metodo do prof. Paes Leme. Creio mesmo que é esta a sua tendencia, pois que este ano os pontos de exames praticos de dissecção por êle organizados, versavam exclusivamente sobre arterias, cerebros e visceras abdominais (HISTORIA..., 1937, p. 425).

Seguindo essa orientação, para o Laboratório de Anatomia da Universidade do Paraná, por ocasião da abertura do curso de Medicina e Cirurgia, foram importados da Europa vários modelos de anatomia humana, para o ensino de anatomia descritiva (UNIVERSIDADE DO PARANÁ, 1913, p. 30). Isto não significava, porém, a inexistência de dissecação de cadáveres no curso. Encontrando um ser humano inerte, na sala de dissecação da Universidade, Romário Martins indagou sobre o fato a Nilo Cairo, que teria respondido: "Que quer? É móda" (HISTORIA..., 1937, p. 426). Num meio tão heterogêneo como a 
Universidade do Paraná, não seria possível impor uma ideia mais apropriada a uma corrente médica vitalista.

A presença das teses homeopáticas na Faculdade de Medicina do Paraná parece indicar um universo de debate e negociação que as fontes analisadas não esclarecem suficientemente. Não se pode afirmar que a Faculdade médica criada na capital paranaense tivesse servido exclusivamente aos interesses da homeopatia e de Nilo Cairo, seu ardente defensor. Porém, parece difícil não enxergar as influências da homeopatia na instituição, graças às estratégias de Cairo no meio acadêmico, notadamente no curso médico.

É perceptível que a vinda de Nilo Cairo a Curitiba, pouco antes da criação da Universidade do Paraná, faz parte de suas disputas internas dentro do universo médico homeopático, repleto de hererogeneidades e ambiguidades. A história da homeopatia no Brasil pode ser compreendida através de sua luta pelo reconhecimento científico de seus paradigmas e porta-vozes (BOURDIEU, 1996). Na primeira década do século XX, o debate girava em torno da necessidade de formação acadêmica, da inserção da homeopatia neste meio e em estabelecer quais instituições estariam autorizadas a reconhecer a autenticidade de seus praticantes. Nota-se que, à medida que o tempo passa, os homeopatas tendem cada vez mais a utilizar o aparato legitimador da ciência médica, ou seja, os cursos médicos oficialmente reconhecidos.

Por que os biógrafos do médico paranaense parecem ignorar as influências da atuação de Nilo Cairo como homeopata na construção da Universidade do Paraná e de seu curso médico? A memória social possibilita a um grupo conservar tanto a ideia de continuidade quanto de mudança histórica, sendo a lembrança uma possibilidade de se relacionar com o passado, reelaborando o que ocorreu. A memória não é uma recapitulação do passado como ele foi e sim uma recondicionalização do passado segundo as lentes do presente (JOVCHELOVITCH, 2011, p. 141).

Pensando na reelaboração da memória sobre Nilo Cairo e a fundação da Universidade do Paraná, compreende-se a dificuldade de seus biógrafos em enxergar o vínculo entre a fundação da Faculdade de Medicina do Paraná e a atuação homeopática de seu idealizador. Para Jurandir Manfredini, ex-aluno da Faculdade de Medicina do Paraná e psiquiatra diretor do Serviço Nacional de Doenças Mentais na década de 1930, era difícil até mesmo compreender como uma Universidade e seu curso médico haviam sido criados por um homeopata positivista. Sua reconstrução de Nilo Cairo ora busca enaltecer o médico, ora o critica, mas o tempo todo parece justificar e minimizar sua ligação com o Positivismo ou a Homeopatia. Parece não caber, para um médico da década de 1930, o estabelecimento de um curso médico acadêmico vinculado a essas duas filosofias. 
O historiador David Carneiro, por sua vez, busca produzir um Nilo Cairo coerente com suas certezas positivistas, que estabelece a Universidade do Paraná graças à sua convicção da necessidade de investir em educação. Sua atuação médica homeopática é decorrente dessa vocação maior que o vincula ao ensino médico, sendo a fundação da Universidade o cume de suas aspirações positivistas.

Para Galhardo, a carreira de Nilo Cairo como homeopata é mais evidente. Porém, o interesse pelo homeopata paranaense parece se encerrar com sua ida para Curitiba e a idealização da Universidade do Paraná. Interessante pensar na função memorialística do livro do Primeiro Congresso Homeopático Brasileiro como mecanismo de reconstrução de um passado de forma a contar uma história de sucessos e vitórias. Dentro desta estratégia, as dissidências, tensões, disputas e discursos heterogêneos são apagados, dando lugar a um tempo pretérito que anuncia um futuro brilhante. Esta memória homogênea só poderia ser construída se situações dissidentes, como o projeto frustado de criação da Sociedade Homoeopathica Brazileira, fossem indelevelmente apagadas da escrita sobre o passado da homeopatia.

\section{REFERÊNCIAS}

ACTA da 13. a sessão ordinaria de 1911-1912. Annaes de Medicina Homoeopathica, Rio de Janeiro, ano 11, n. 5, p. 250, maio 1912a.

ACTA da 16. ${ }^{a}$ sessão ordinaria de 1911-1912. Annaes de Medicina Homoeopathica, Rio de Janeiro, ano 11, n. 6, p. 276, jun. 1912b.

ACTA da 19. a sessão ordinária de 1911-1912. Annaes de Medicina Homoeopathica, Rio de Janeiro, ano 11, n. 6, p. 284-286, jun. 1912c.

ACTA da 25. ${ }^{a}$ sessão ordinária de 1911-1912. Annaes de Medicina Homoeopathica, Rio de Janeiro, ano 11, n. 9, p. 376-377, set. 1912d.

BOURDIEU, P. A economia das trocas linguísticas. São Paulo: EDUSP, 1996.

CAIRO, N. Algumas reflexões. Revista Homoeopathica Brazileira, Curitiba, ano 7, n. 2, p. 25, fev. 1912a.

. Degeneração. Revista Homoeopathica Brazileira, Curitiba, ano 7, n. 3-4, p. 40-42, mar./abr. 1912 b.

. Editoriaes. Revista Homoeopathica Brazileira, Curitiba, ano 6, n. 11-12, p. 3 , nov./dez. 1911 
. Elementos de Physiologia. Curityba: Universidade do Paraná, 1916.

. Faculdade de Medicina Homoeopathica do Rio de Janeiro. Revista Homoeopathica Brazileira, Curitiba, ano 7, n. 6, p. 70-71, jun. 1912c.

. Nosso programa. Revista Homoeopathica Brazileira, Curitiba, ano 1, n. 1-3, p. 3, jan./mar. 1906 .

. Noticiario. Revista Homoeopathica Brazileira, Curitiba, ano 4, n. 4-6, p. 149150, maio/jun. 1909.

. Uma explicação inevitavel. Revista Homoeopathica Brazileira, Curitiba, ano 6, n. 3-4, p. 71-74, mar./abr. 1911.

. A popularização do Instituto Hahnemanniano do Brazil. Revista Homoeopathica Brazileira, Curitiba, ano 7, n. 7, p. 80-84, jul. 1912d.

. Programma de um curso de Pharmacologia Homeopathica. Revista Homoeopathica Brazileira, Curitiba, ano 7, n. 6, p. 59-61, jun. 1912e.

. Similia Similibus Curantur. Tese (Doutorado em Medicina) - Faculdade de Medicina do Rio de Janeiro, Rio de Janeiro, 1903.

CARNEIRO, D. Nilo Cairo (biografia). Curitiba: UFPR, 1984.

CRUZ FILHO, D. da. Noticiario. Annaes de Medicina Homoeopathica, Rio de Janeiro, ano 11, n. 6, p. 300, jun. 1912.

FACULDADE Hahnemanniana. Annaes de Medicina Homeopathica, Rio de Janeiro, ano 15, n. 7, p. 493, abr. 1914.

GAlHardo, J. E. R. Livro do 1. ${ }^{\circ}$ Congresso Brasileiro de Homoeopathia. Rio de Janeiro: Instituto Hahnemanniano do Brasil, 1928.

GIORDAN, A.; RAICHVARG, D. Los Orígenes de la homeopatia. Lyon: Boiron, 2010. HISTÓRIA da Universidade do Paraná. Revista Medica do Paraná, Curitiba, ano 6, n. 11-12, p. 425, nov./dez. 1937.

JOVCHELOVITCH, S. Os contextos do saber. Petrópolis: Vozes, 2011.

LUZ, M. A arte de curar versus a ciência das doenças. São Paulo: Dynamis, 1996.

NOGUEIRA, A. A Faculdade de Medicina Homoeopathica e sua organização. Annaes de Medicina Homeopathica, Rio de Janeiro, ano 11, n. 5, p. 270-272, maio 1912.

PRIVEN, S. I. W. de. Hahnemann: um médico de seu tempo. São Paulo: EDUC, 2005. UNIVERSIDADE DO PARANÁ. Livro de Assentamentos dos Professores da Faculdade de Medicina do Paraná. Curitiba: [s.n.], 1920.

. Programmas do Curso de Medicina e Cirurgia - 3. anno. Curityba: Max Roesner, 1916. 
. Programmas do Curso de Pharmacia - 3. ' anno. Curityba: Cezar Schulz, 1914a.

. Relatorio Geral da Universidade do Paraná apresentado à Assembléa Geral de 19 de dezembro do anno de 1913 pelo Dr. Victor Ferreira do Amaral e Silva. Curityba: Alfredo Hoffman, 1913.

- Relatorio Geral da Universidade do Paraná apresentado à Assembléa Geral de 19 de dezembro do anno de 1914 pelo Dr. Victor Ferreira do Amaral e Silva. Curityba: Alfredo Hoffman, 1914b.

- Relatorio Geral da Universidade do Paraná apresentado à Assembléa Geral de 19 de dezembro do anno de 1915 pelo Dr. Victor Ferreira do Amaral e Silva. Curityba: Max Roesner, 1915.

UNIVERSIDADE FEDERAL DO PARANÁ. Centenário de nascimento do Professor Nilo Cairo. Curitiba: UFPR, 1974.

Texto recebido em 16 de setembro de 2014 . Texto aprovado em 15 de outubro de 2014. 
